\title{
PFC/RR-92-14
}

\section{CICC Retrofit Magnet}

\author{
Quarterly Progress Report \\ Contract No. DE-FG22-90PC90350 \\ July 1992 \\ R. Leonard Myatt and P.G. Marston
}

Submitted October 30, 1992

\section{DISCLAIMER}

\begin{abstract}
This report was prepared as an account of work sponsored by an agency of the United States Government. Neither the United States Government nor any agency thereof, nor any of their employees, makes any warranty, express or implied, or assumes any legal liability or responsibility for the accuracy, completeness, or usefulness of any information, apparatus, product, or process disclosed, or represents that its use would not infringe privately owned rights. Reference herein to any specific commercial product, process, or service by trade name, trademark, manufacturer, or otherwise does not necessarily constitute or imply its endorsement, recommendation, or favoring by the United States Government or any agency thereof. The views and opinions of authors expressed herein do not necessarily state or reflect those of the United States Government or any agency thereof.
\end{abstract}

\author{
Massachusetts Institute of Technology \\ Plasma Fusion Center \\ 175 Albany Street \\ Cambridge, MA 02159
}

$$
\text { Miviter }
$$




\subsection{Introduction and Structural Design Concept}

The coil system presented here for the MHD retrofit magnet incorporates many features of the latest in superconducting magnet technology and finite element modeling to create an efficient and viable design concept. At the core of the design is the niobium titanium (NbTi) superconducting Cable-in-Conduit Conductor (CICC). Engineered to create moderately high magnetic fields (up to $8 \mathrm{~T}$ ) with essentially no power loss, this specific CICC design provides good load carrying capacity, operating margin from a perturbation such as a local heat input, and coil protection in the event of a quench transient.

The CICC is wound on a mandrel into long, tapered, saddle shaped single conductor thickness pancakes. By defining the appropriate number of conductor turns in each pancake, the saddle coils can be stacked to form a semi-elliptical winding pack cross section (see Figs. 1.1 and 1.2). Extruded aluminum filler brocks are fitted into the steps at the edge of the pancake and present a smooth surface to the supporting structure.

The semi-elliptical conductor array is supported by an identically shaped strap at all locations except where the end turns sweep over the MHD channel. The strap resists the electromagnetic forces tending to separate the coils on each side of the channel. Low friction surfaces are placed between conductor pancakes, and between the inside skin of the support straps and the ouside surface of the conductor winding pack. This allows relativ movement between pancakes, and between the strap and coil, thereby reducing shear stresses and coulombic friction heating which would otherwise tend to crack insulation, load joints, and initiate a quench in the superconducting cable.

The end turn geometry is carefully chosen to produce a smooth cross-over configuration within reasonable dimensions. A minimum bend radius of $30 \mathrm{~cm}$ is established as discussed later in this report. The elliptical cross section is maintained throughout the end turn as a key part of maintaining small stress concentrations and the desired section properties. The winding pack sweeps out $4 j^{\circ}$ from the vertical midplane of the machine to clear the channel. From there, the geometry is swung out and around the channel to complete the end turn. The end turn region is supported by a $10 \mathrm{~cm}$ thick gussetted aluminum plate.

The strap system and end turn support plates are welded to a $5 \mathrm{~cm}$ thick high strength aluminum box beam which initially serves as a coil assembly frame. The box is also the structural member which carries some of the axial load created by the end turns. The forces in the end turn tend to collapse the saddle, and if unsupported, would expell the end turn support structure like a watermelon seed pinched between two fingers. 


\subsection{Stress Analysis}

The basic methodology used to analyze the MHD electromagnet and structure is based on finite element modeling. Finite element analysis (FEA) is a powerful tool which has evolved significantly over the past decade. In earlier days, structural design and analysis was done by simplified hand calculations requiring crude approximations. Now, an accurate FE model can be used to understand every characteristic and detail of a given structure. This also provides a means of improving and optimizing the basic design, since changes in the FE model are easily made and the results are quickly evaluated.

The ANSYS ${ }^{1}$ finite element computer program is used to approximate the actual behavior of the machine. The finite element model approximating the coil and structure as a well defined collection of brick and interface gap "elements," and from a distance, this model look a lot like the actual machine.

\subsection{The Finite Element Model}

The analysis described here is designed to evaluate the complex 3-D behavior of the dipole coil and support structure. The electromagnetic and structural evaluations are based on a 3-D nonlinear finite element analysis of the proposed MHD coil and support concept. The finite element model ignores the slight taper in the magnet system which allows the use of three symmetry planes thereby greatly reducing the model size and computational time.

The winding pack cross section with a nominal build of 0.72 meter width wind 0.88 meter half height represents a coil which operates right at the design current density of about $13 \mathrm{MA}$ turns $/ \mathrm{m}^{2}$. The analysis assumes zero friction between the coil and the strap. Although not entirely true, this assumption is necessary due to the size and complexity of the 3-D nonlinear model. The ref. 1 report discusses the effects of friction on the stresses in the coil, and indicates that relative motion between the strap and the coil is an essential part of the design concept.

The model is generated within the ANSYS PREP7 preprocessor. Fundamental dimensions are defined by parameters which greatly simplify the inevitable changes to the model which occur during the design and analysis process. Changes such as mesh density, coil build, end turn support plate tinicknesses and crossover radii can all be accommodated by simply redefining numbers in the parameter list. Figures 2.1-1 to 2.1-3 show the finite element model in some detail.

\subsection{Material Properties}

The nature $r$ f the analysis and its objectives establish the level of detail that must be included in the model. On this basis, the actual winding pack (i.e., insulation, conductor, conduit) is approximated by smeared orthotropic material properties.

Modulus of Elasticity:

$$
\begin{gathered}
\mathrm{E}_{\mathrm{x}}=\mathrm{E}_{\mathrm{z}}=28 \mathrm{GPa} \text { (Transverse) } \\
\mathrm{E}_{\mathrm{y}}=58 \mathrm{GPa} \text { (Longitudinal) }
\end{gathered}
$$


Shear Modulus:

Poisson's Ratio:

$$
\begin{aligned}
\mathrm{G}_{\mathrm{xy}} & =7 \mathrm{GPa} \text { (Trans-Long) } \\
\mathrm{G}_{\mathrm{yz}} & =20 \mathrm{GPa} \text { (Long-Trans) } \\
\mathrm{G}_{\mathrm{z}} & =9 \mathrm{GPa} \text { (Trans-Trans) }
\end{aligned}
$$

$v_{x y}=0.30$, ans Strain from Long Stress)

$v_{y z}=0.16$ (Long Strain from Trans Stress)

$v_{x z}=0.24$ (Trans Strain from Trans Stress)

These properties are calculated such that the global structural characteristics of the saddle coil are represented. The material properties associated with the strap, end turn support plates, and gussets are simply isotropic constants.

\subsection{Boundary Conditions and Solution Process}

Displacement boundary conditions for the structural analysis provide for full machine behavior by specifying zero displacements across the three symmetry planes. The model is loaded electromagnetically by a uniform current density of $13.05 \times 10^{6} \mathrm{~A} / \mathrm{m}^{2}$, which produces a nominal 4.5 tesla at the machine axis. The first pass of the analysis solves the electrical problem. One end of the coil is set to zero potential, while a known current is applied at the other. The current density is essentially uniform across the build of the coil, as it must be in a superconducting application. The second pass of the analysis solves the magnetics problem. $\mathrm{J} \times \mathrm{B}$ body forces are also calculated and saved automatically as input to the next pass of the analysis which is the structural solution. The analysis is complete when the nonlinear gap elements have converged as the coil strains and slips within the confines of the supporting structure.

\subsection{Structural Details}

During the coil manufacturing process, the conductor is bent to form the end turns of the magnet. Plastic deformation occurs, which is often called keystoning as it describes the shape of the deformed cross section (see Fig 2.4-1). The amount of distortion is inversely proportional to the bend radius. For large radii, the effect is small and the distortion is minimal. An end turn with a large bend radius is inefficient as it consumes valuable space and material, and locally degrades the quality of the magnetic field. An end turn with a small bend radius is compact and efficient, but results in an array of oddly shaped conductors which, as a result, load and strain with non-uniformities. Therefore, establishing a minimum bend radius requires striking a compromise. The permanent strain $(\delta)$ can be quantified by the following simple equation:

$$
\delta=\mathrm{t}^{2} / 8 \mathrm{r}
$$

where $t$ is the thickness of the conduit, and $r$ is the bend radius. The maximum deformation is chosen to be $0.5 \mathrm{~mm}$, which establishes a minimum bend radius of about $30 \mathrm{~cm}$. 
Although the conductor winding pack represents a significant structural cross section, the electromagnetic forces in the end turn region are high and tend to collapse the opposing coils. These forces are resisted by reinforced support plates which are located under the end turn winding packs. The construction of these plates is limited locally by the distance between the coil and the channel. Outboard of the channel the plates are well reinforced by gussets which span the distance between the two end turns.

\subsection{Stress Results}

The results of the analysis are best summarized by the graphical output from the computer finite element model. The following is a series of plots depicting the stresses in the various components of the system.

Figure 2.5-1 shows the tresca stress intensity in the support shell, which extends the length of the straight section and into the first bend region of the end turn. The nominal stress in the $2 "$ thick shell is about $150 \mathrm{MPa}$, and peaks to $270 \mathrm{MPa}$ in a very small localized region at the tight bend. This high stress can be relieved by altering the structure in that particular region.

Figure 2.5-2 shows the tresca stress intensity in the shell extension. Ignoring the region where the st ell tapers to a knife edge, all the stresses are also $150 \mathrm{MPa}$ and below.

Figure 2.5-3 shows the stresses in the end turn support plate which carries the winding pack up and over the channel. The vast majority of stresses within the structure are below 200 $\mathrm{MPa}$. As with the shell extension, there is a local region of high stress due to the sharp taper where the two coils diverge to form the end turn.

Figure 2.5-4 shows the tresca stress intensity in the gusset plates which bridge the span between the upper and lower support plates at each end of the magnet system. The stresses shown here are all below $100 \mathrm{MPa}$, and pose no threat to the structural integrity of the design. However, in the actual design, these plates are joined and closed off by a cover plate, adding

rigidity and stability to an otherwise open section.

Figure 2.5-5 shows the tresca stress intensity in the aluminum sheath, the structural element of the conductor winding pack. At the magnet midplane the stresses match those of the 2-D analysis of reference 1 . Stresses peak at about $110 \mathrm{MPa}$ in the transition region between the end turn and straight section. Stresses at the end turn mid-span, directly above the channel centerline, peak at about $80 \mathrm{MPa}$, an indication that the end turns are well supported by the gusseted plate design presented here.

\subsection{References}

1. R.Leonard Myatt and P.G. Marston, "DC CICC Retrofit Magnet Preliminary Design, Software Development and Analysis Report," DOE/PC-90350-4, Submitted February 10, 1992, MOT Plasma Fusion Center, Cambridge, MA 


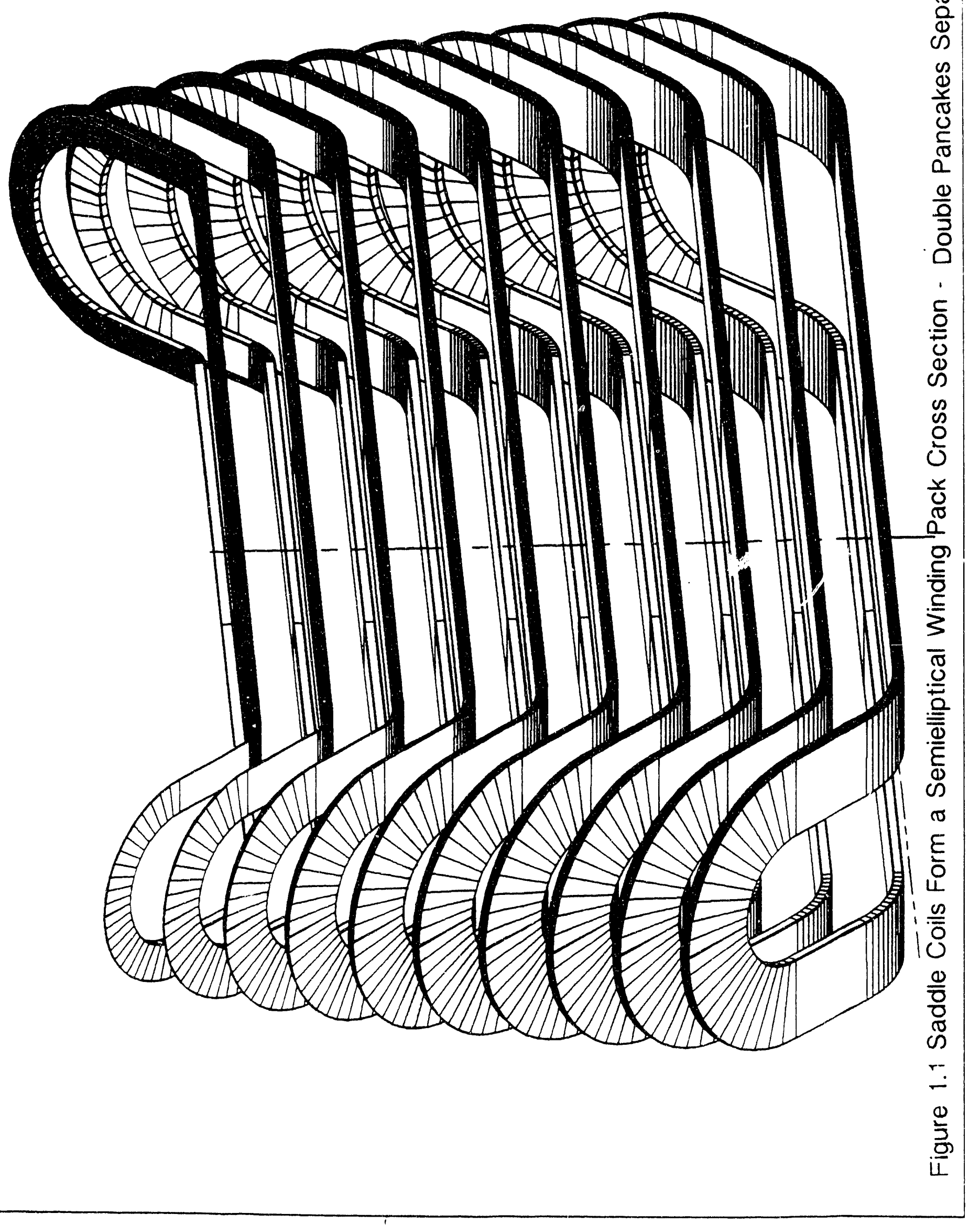




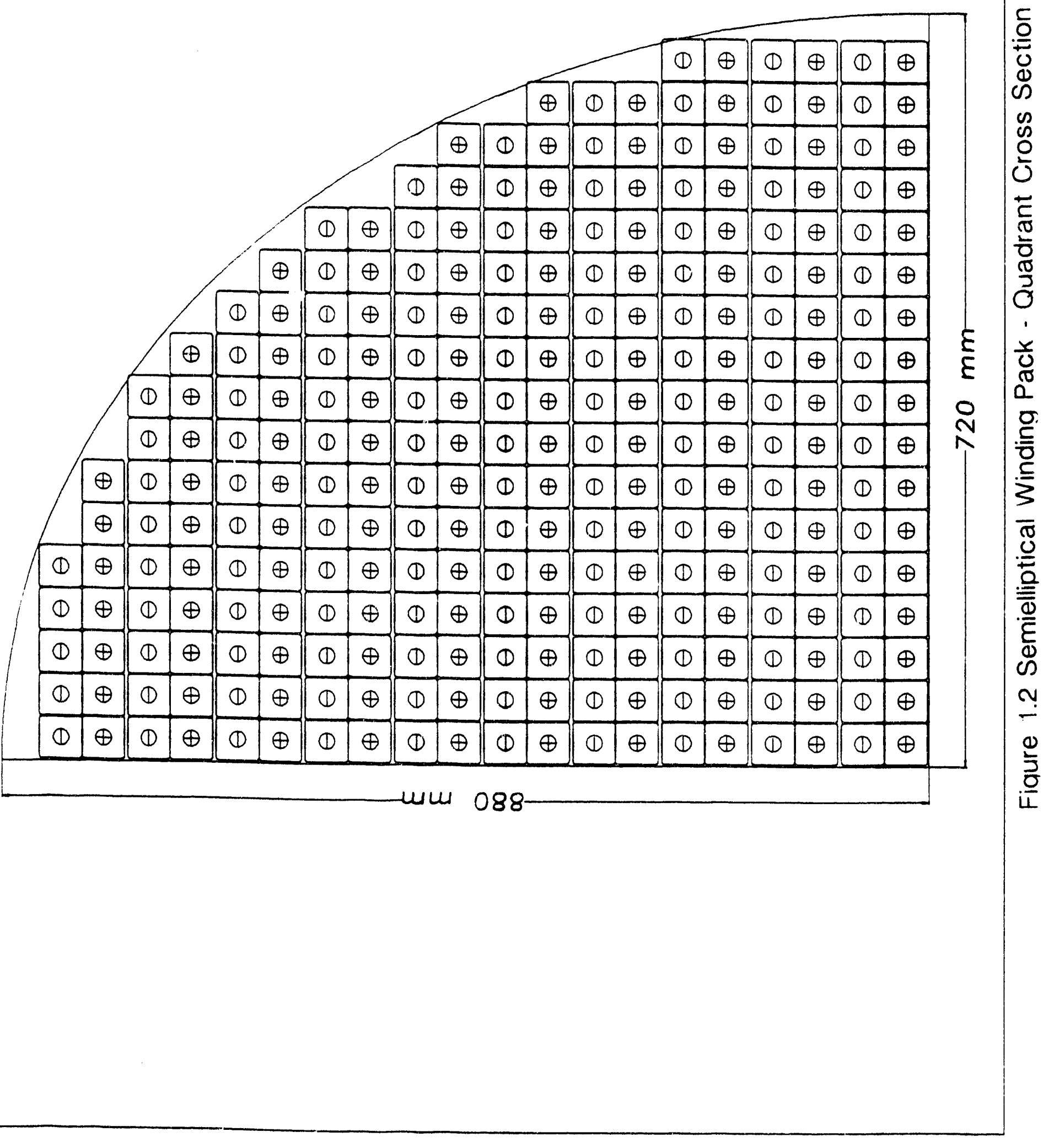




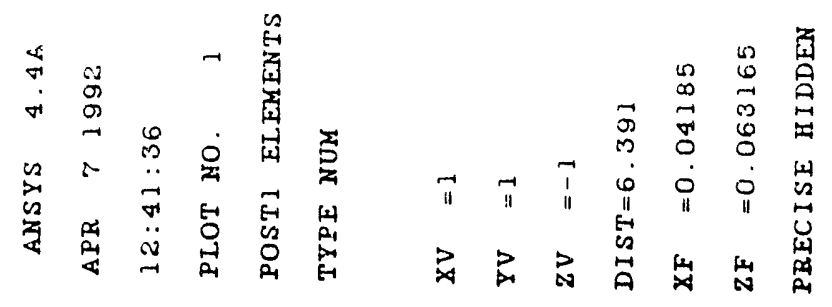

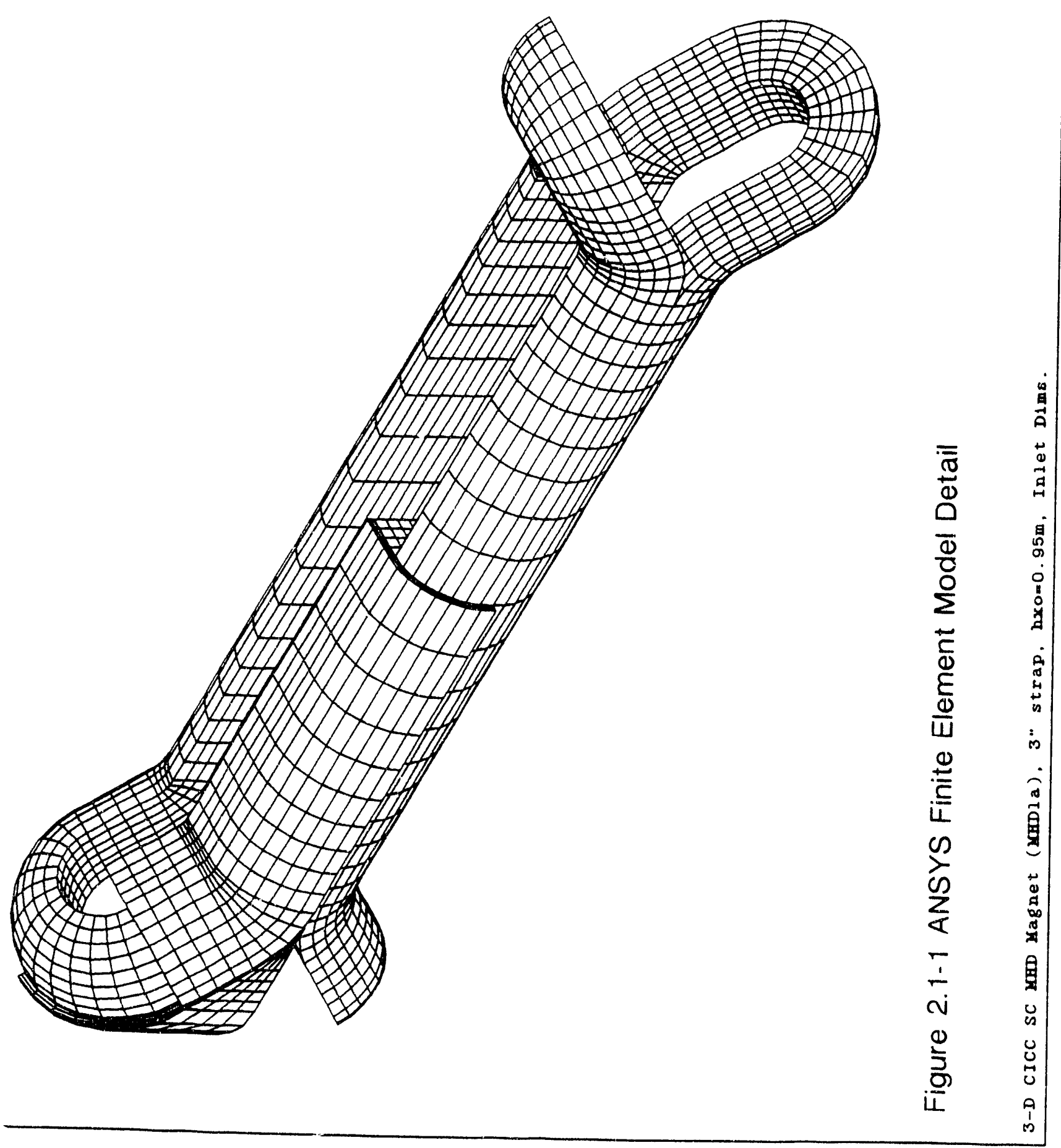




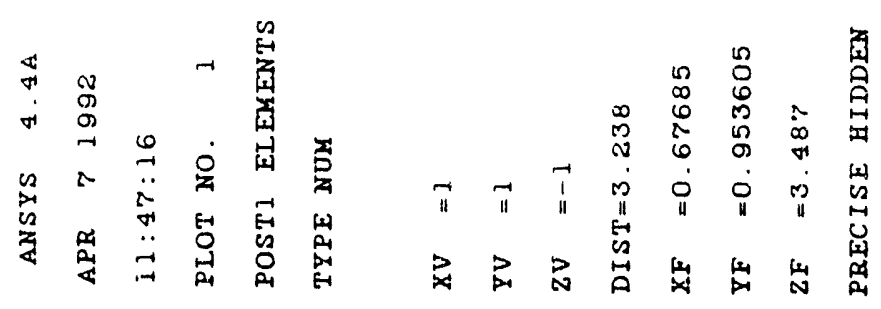

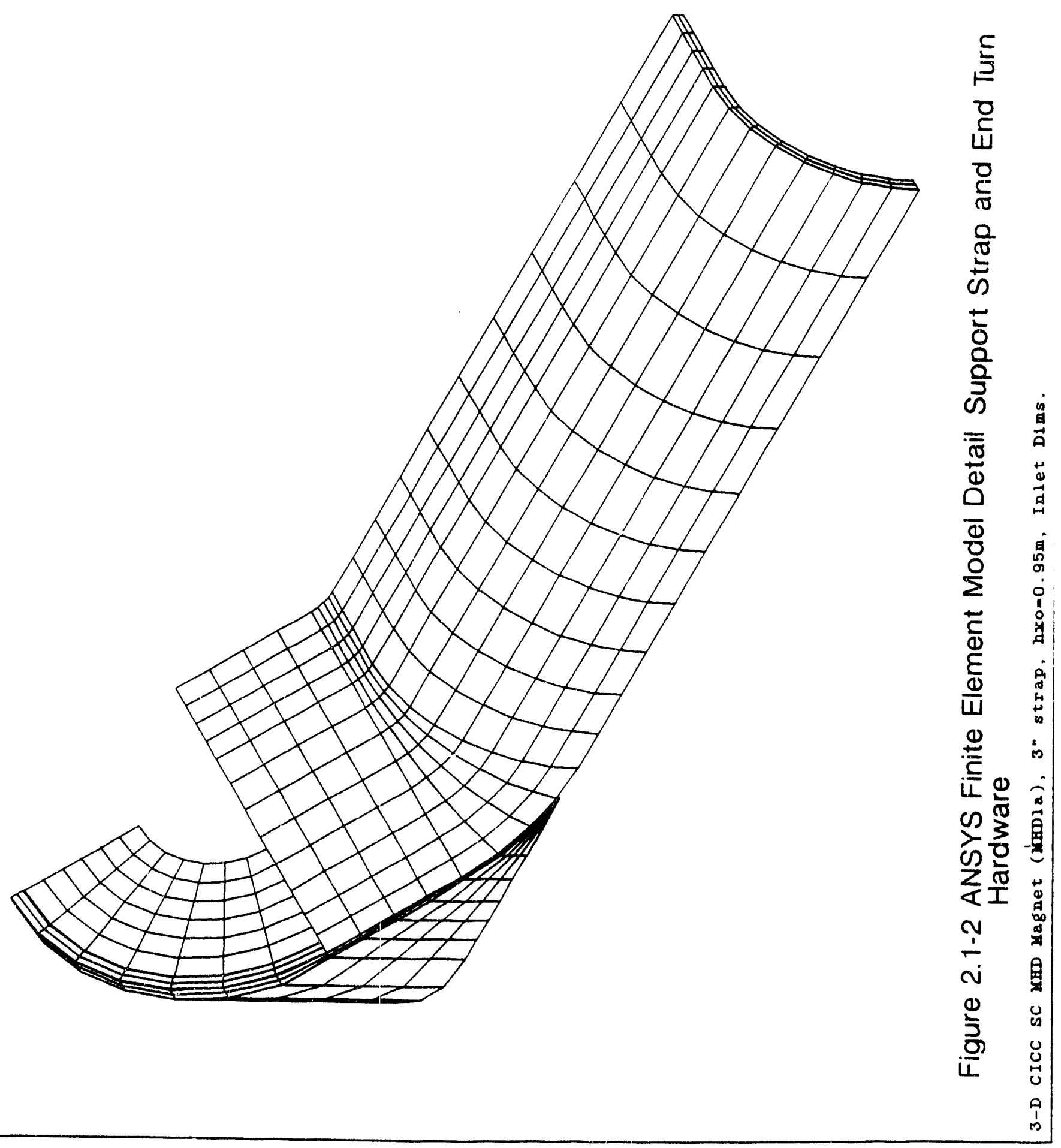




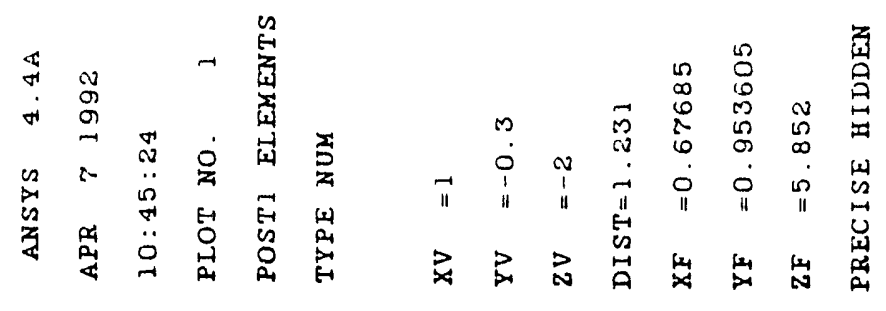

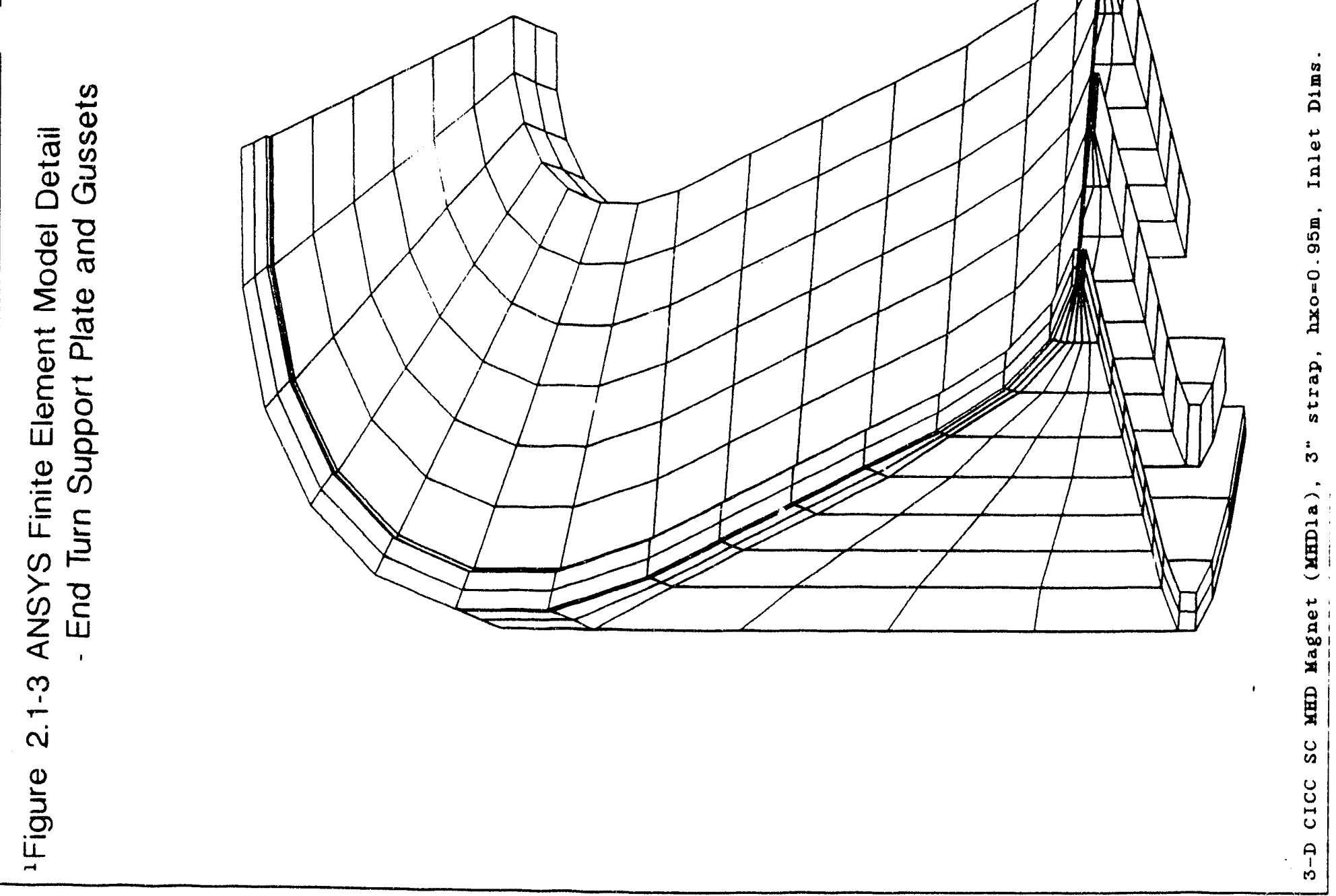




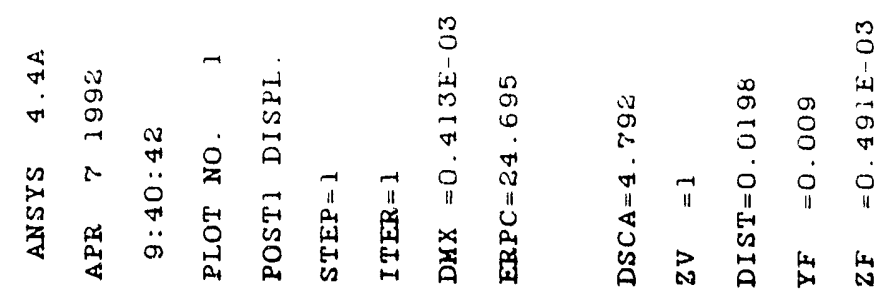
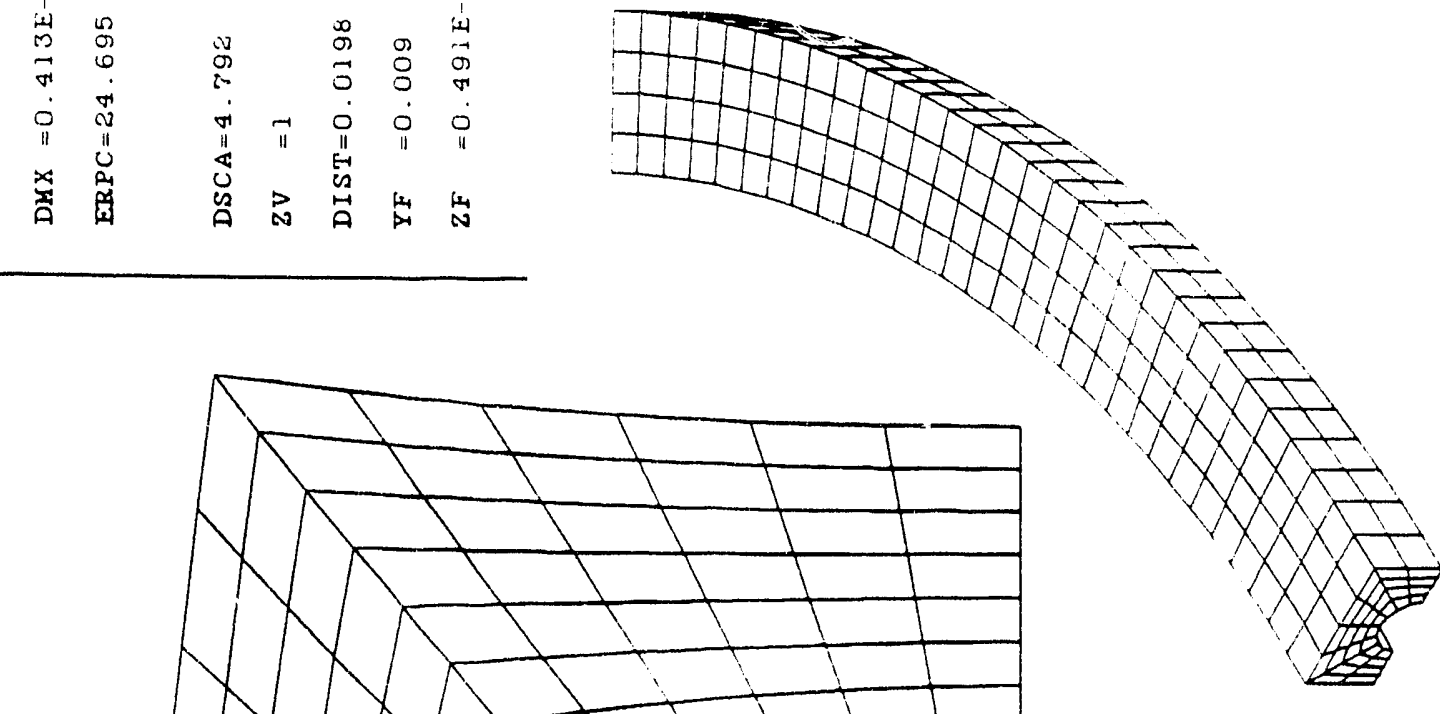

$\mid$

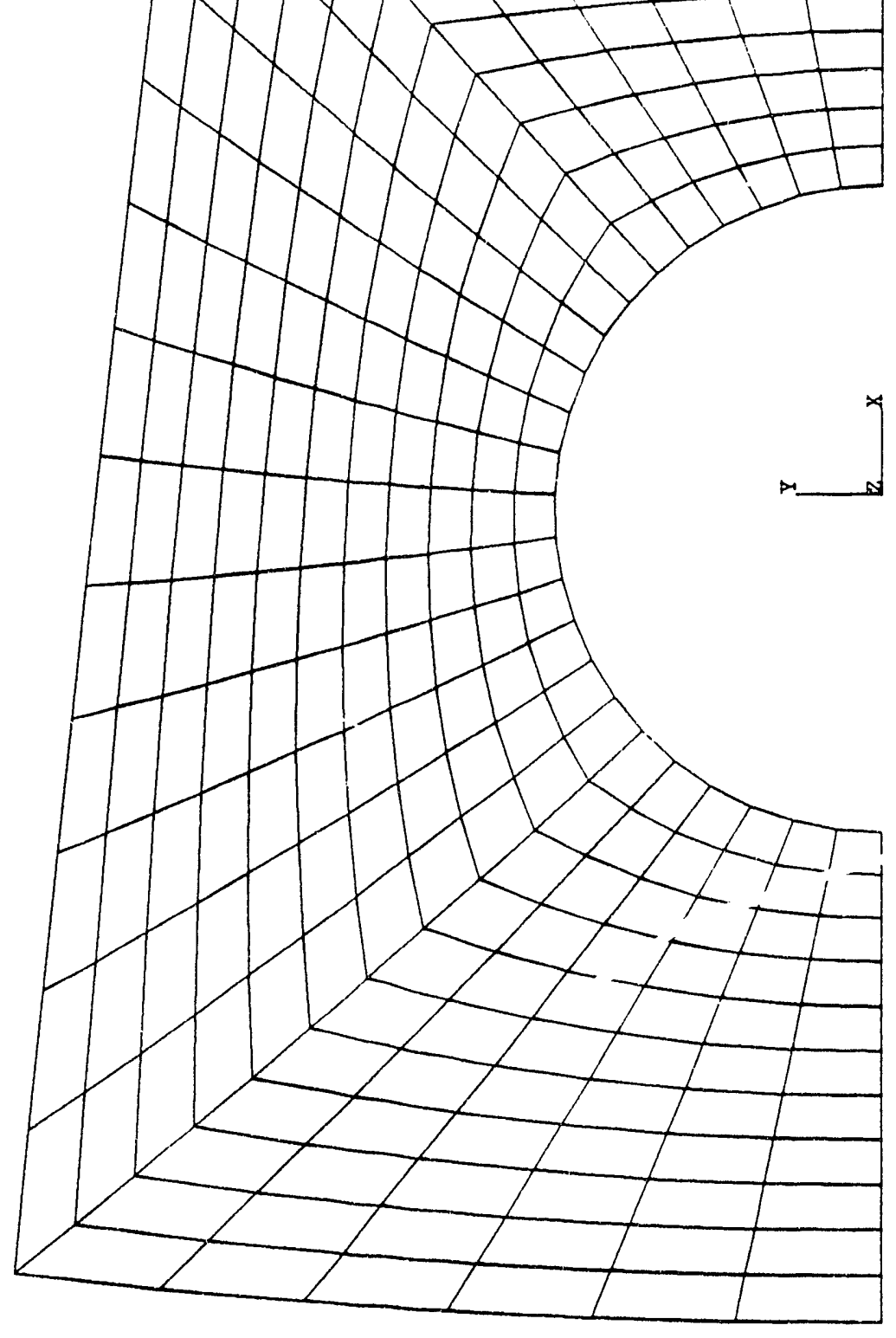

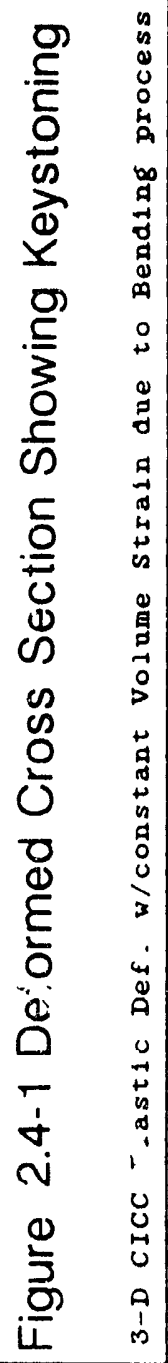




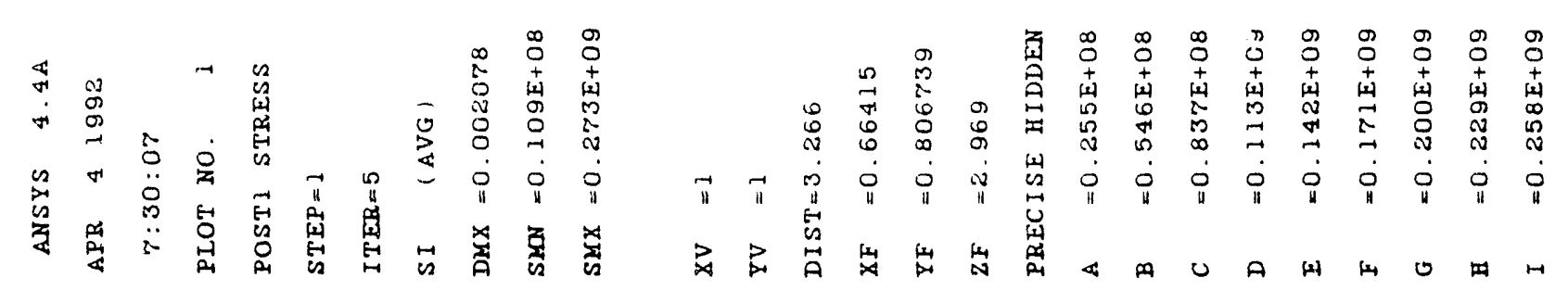

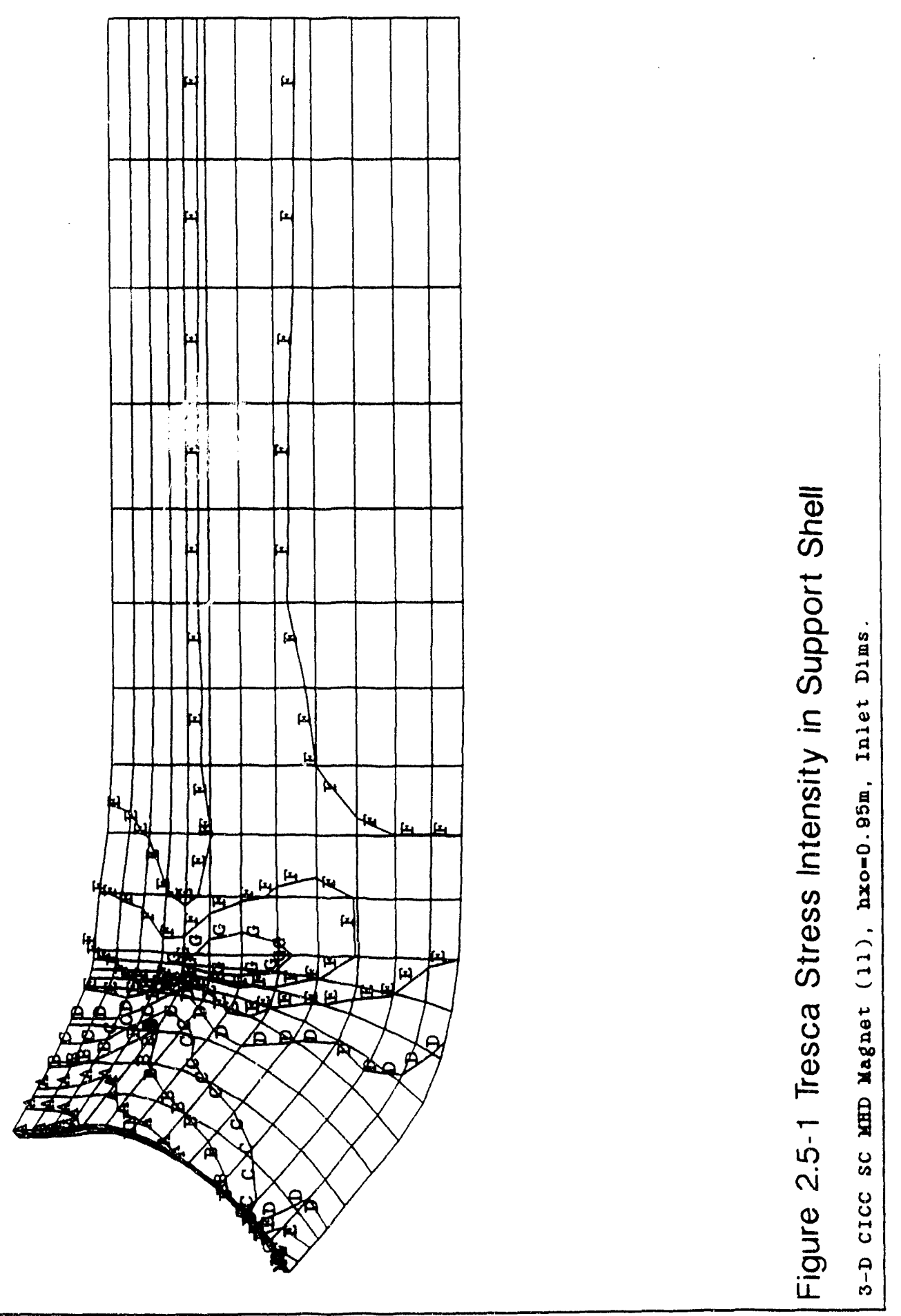



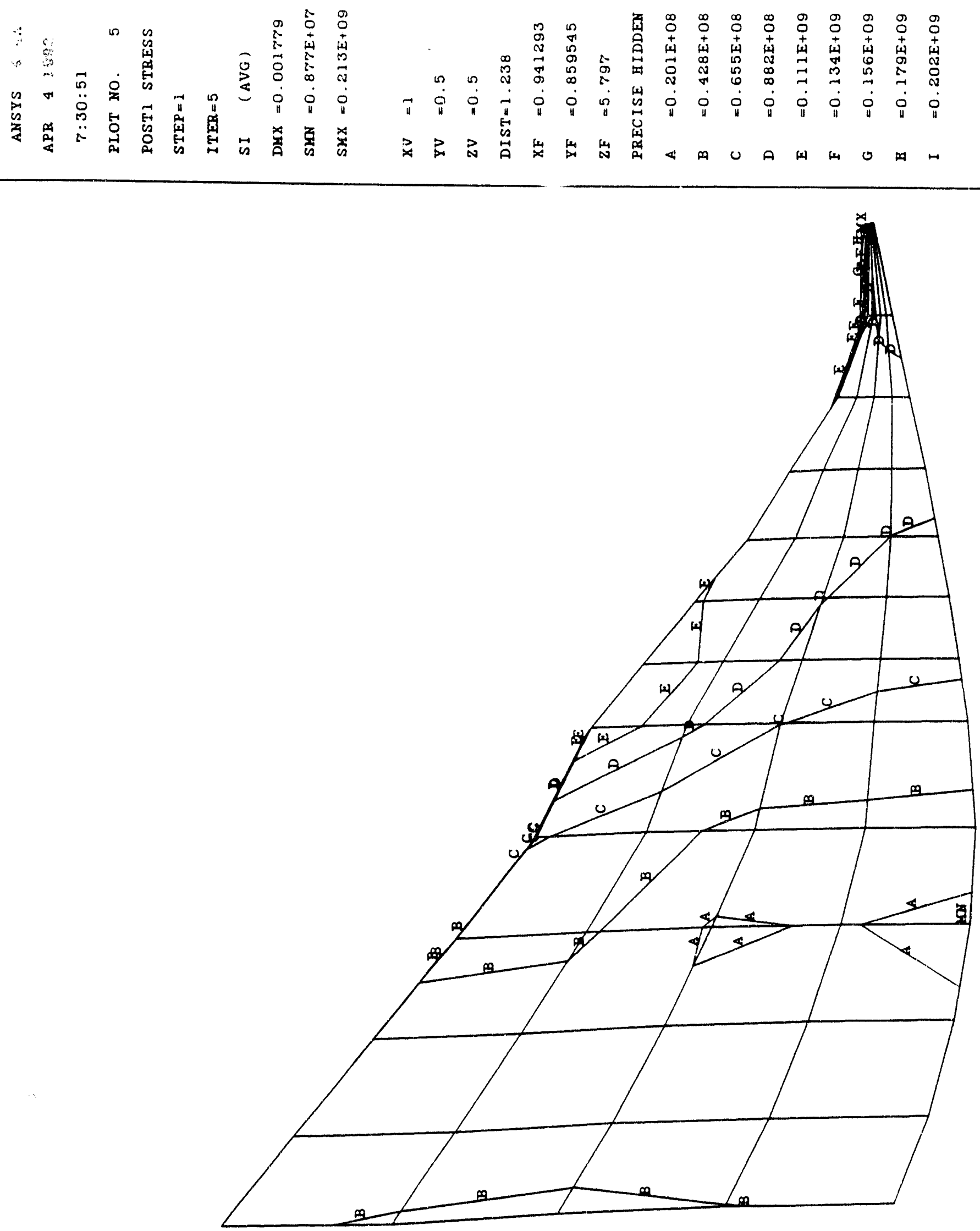

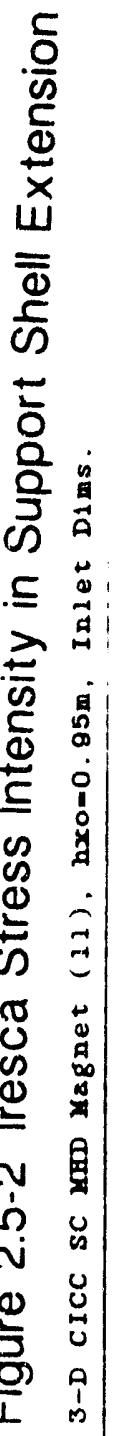



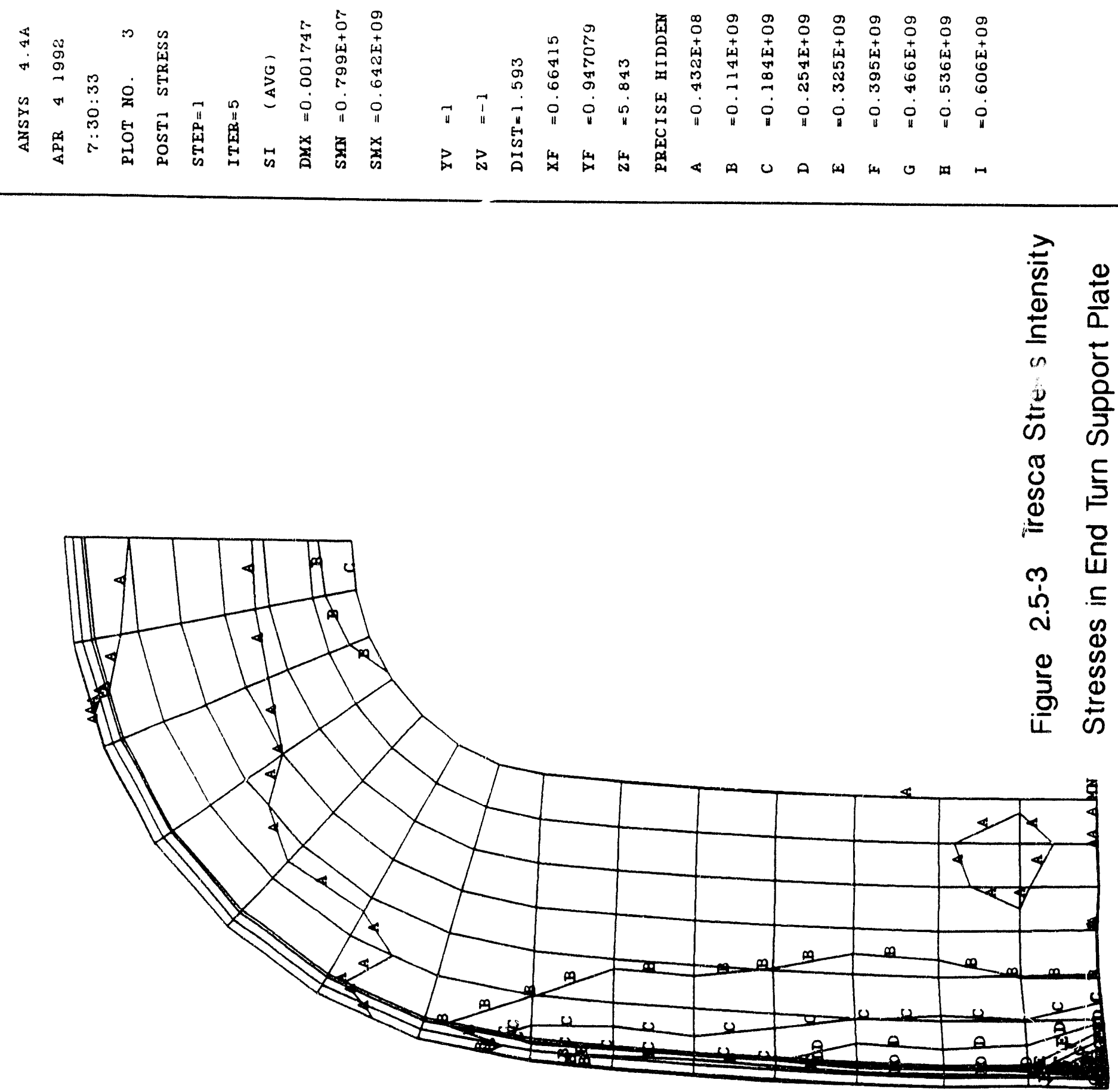

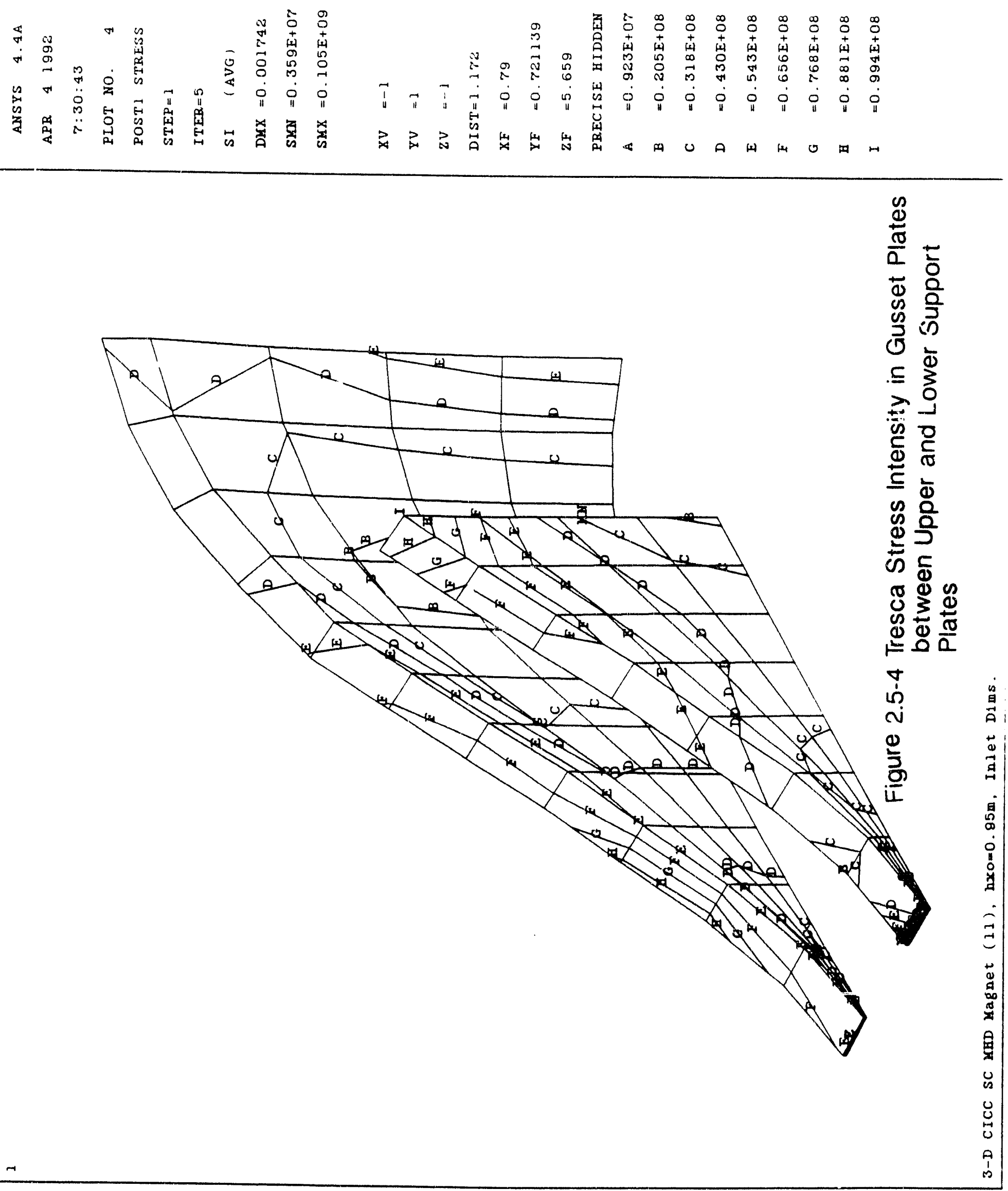


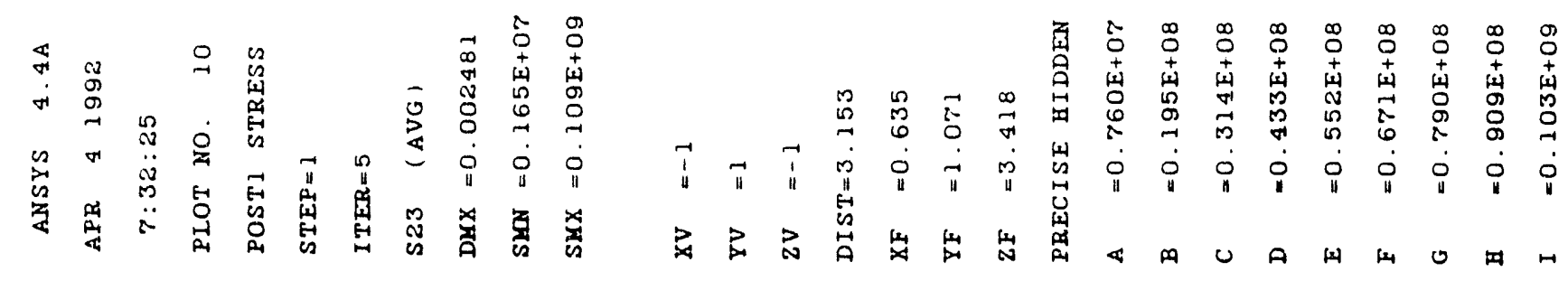
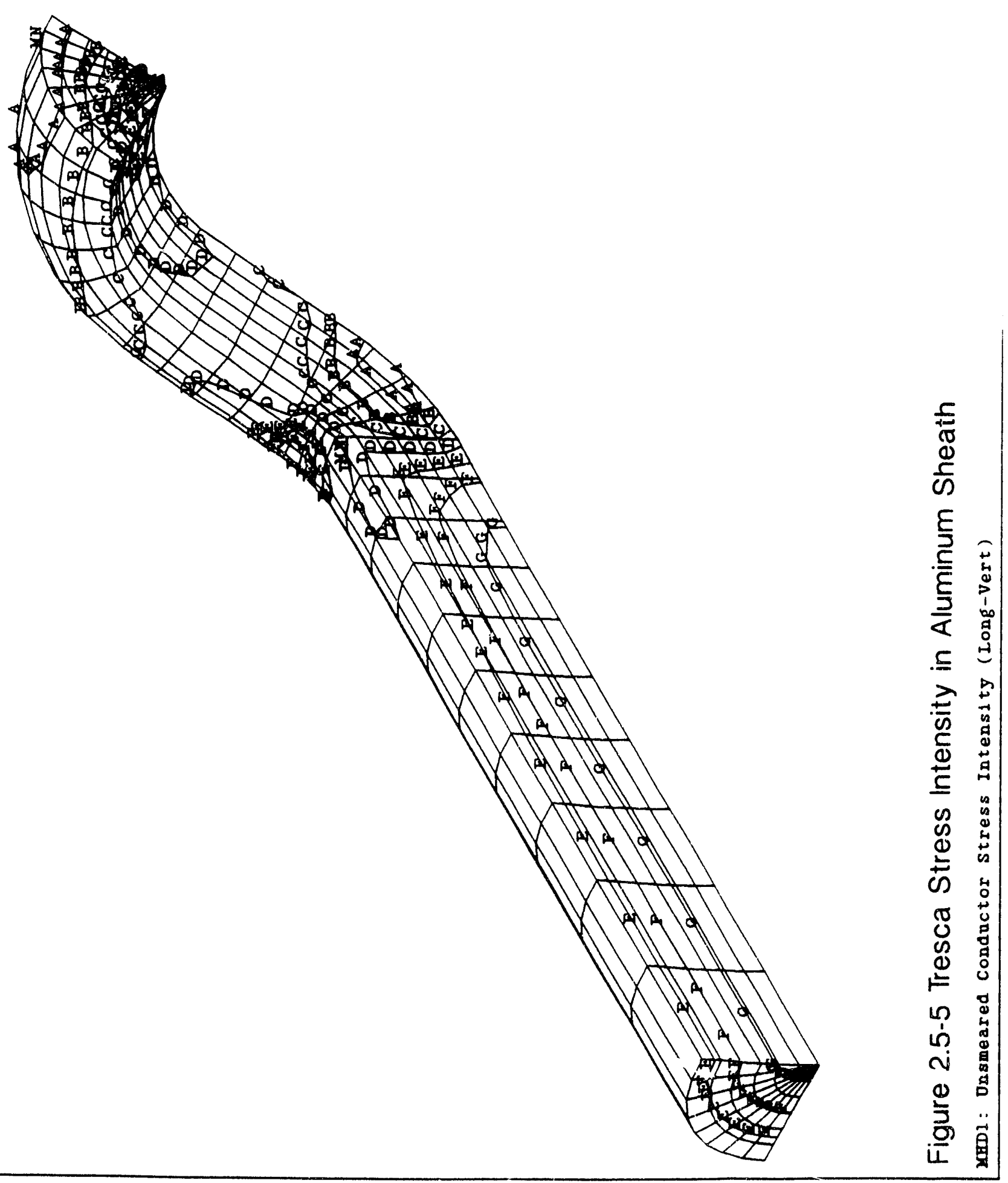

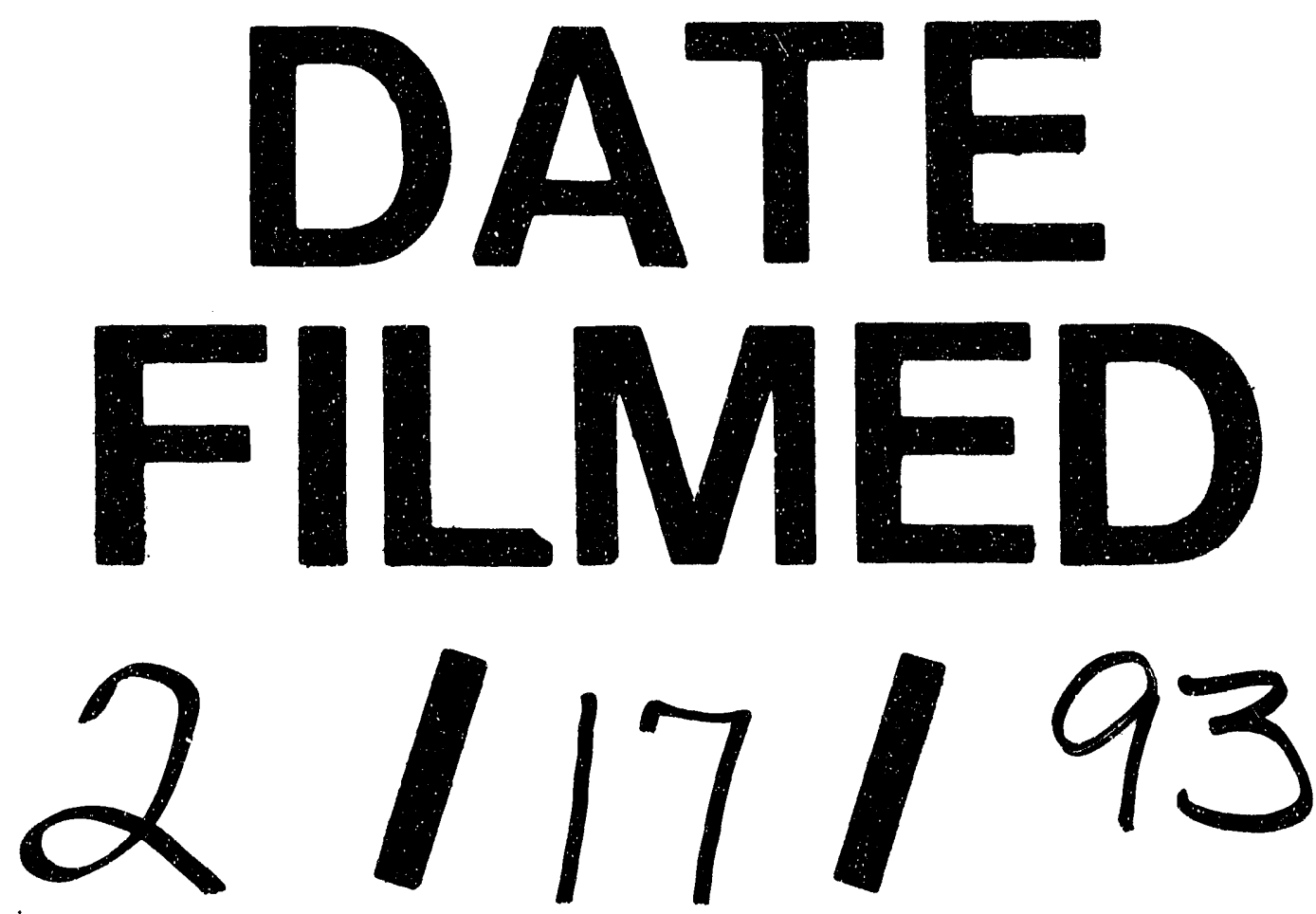
